Creso Alberto Bem de Almeida

(1) https://orcid. org/0000-0002-0106-6066

Luiz Felipe da Silva Figueiredo 1,2,3

Ohttps://orcid.org/0000-0003-1434-742X

Jéssica Plácido

OChtps://orcid.org/0000-0003-1921-6672

Felipe de Oliveira Silva

Ohttps://orcid.org/0000-0002-1457-0480

Paulo de Tarso Maciel-Pinheiro ${ }^{4}$

Ohttps://orcid.org/0000-0002-3358-4386

Renato Sobral Monteiro-Junior $r^{4,5}$

https://orcid org/0000-0002-8472-262X

Andrea Camaz Deslandes ${ }^{1}$

o https://orid.org/0000-0001-5941-9111

Jerson Laks ${ }^{1,3}$

Ohttps://orcid.org/0000-0002-5129-9087

\section{Floor Maze Test as a predictor of cognitive decline in older adults living in nursing homes}

\author{
Floor Maze Test como preditor de declínio cognitivo em idosos \\ residentes de instituições de longa permanência
}

DOI: $10.1590 / 0047-2085000000271$

\section{RESUMO}

Objetivo: Pesquisas em instituições de longa permanência para idosos (ILPI) mostram uma associação entre o aumento de risco de declínio cognitivo e o comprometimento das habilidades de navegação espacial dos idosos. A navegação espacial pode ser definida como uma habilidade complexa, que depende de funções cognitivas e motoras, emergindo como um importante marcador de estadiamento da demência. O presente estudo teve por objetivo comparar a navegação espacial de idosos saudáveis; institucionalizados e com demência Métodos: Foi realizado um estudo de corte transversal com 78 idosos (saudáveis $=37$, demência $=22$, institucionalizados $=19$ ) avaliados por meio do Miniexame do estado mental (MEEM), Floor Maze Test (FMT) e 8-foot-up-and-go (8UG). Uma ANOVA One-way foi realizada para comparar os grupos. Resultados: Como esperado, o grupo saudável foi mais ágil, tanto no FMT imediato $\left(X^{2}=31,23 ; p<0,01\right)$ quanto no tardio $\left(X^{2}=41,21 ; p<0,01\right)$. Quando comparados os grupos demência e institucionalizados, não houve diferença significativa no MEEM e FMT tardio. Porém, os idosos institucionalizados mostraram piores resultados que o grupo demência no FMT imediato $(p<0,01)$ e no teste $8 \cup G(p<0,01)$. Conclusão: Os resultados indicam um pior desempenho na navegação espacial, função executiva e habilidades motoras dos idosos em ILPI e com demência. A possibilidade de idosos institucionalizados serem subdiagnosticados deve ser considerada.

\section{PALAVRAS-CHAVE}

Floor Maze Test, institucionalização, idosos, declínio cognitivo, demência.

\section{ABSTRACT}

Objective: Long-term care facilities (LTCF) are associated with an increased risk of cognitive decline and impairment in spatial navigation abilities. Recent studies have demonstrated that spatial navigation as a complex skill, involving cognitive and motor functions, emerging as a new marker for the progression of dementia. The present study aims to compare spatial navigation in healthy, institutionalized, and AD elderly subjects. Methods: In a cross-sectional study, we evaluated 78 elderly individuals (healthy $=37, \mathrm{AD}=22$, institutionalized $=19$ ) using the Mini-Mental State Examination (MMSE), Floor Maze Test (FMT) and 8-foot-up-and-gotest (8UG) to assess global cognitive function, spatial navigation and motor function, respectively. Results: In the FMT, the immediate maze time (IMT) and delay maze time (DMT) were significantly shorter in the healthy group than those of the institutionalized and AD groups $\left(X^{2}=31.23 ; p<0.01\right)$ and $\left(X^{2}=41.21 ; p<0.01\right)$, while there were no significant differences between the $A D$ and institutionalized groups in terms of the DMT and MMSE results. However, the institutionalized group showed worse results in terms of IMT $(p<0.01)$ and 8 UG $(p<0.01)$ than those in the dementia group. Conclusion: Our results indicate that both institutionalized older people and patients with Dementia have a deficit in the spatial navigation ability, cognitive functions and motor skills. We should consider that there might be a possibility of underdiagnosis in institutionalized older people.

\section{KEYWORDS}

Floor Maze Test, institutionalized, elderly, cognitive decline, dementia. 


\section{INTRODUCTION}

Alzheimer's disease (AD) is the most common form of dementia' and the cost estimates have improved, which reflects on economic burnout, with cost of approximately $\$ 818$ billion². Functional dependency and cognitive decline are the major causes of institutionalization as a result of residence long-term social and nursing care facilities (LTCF) ${ }^{3}$.

Recent studies suggested that who have become institutionalized present more cognitive decline than those who remain in the community ${ }^{4-6}$. Institutionalization leads to a reduction in the motor demands inherent in social life and shows an important relationship with the decrease in cognitive abilities?. In general, the physical activities undertaken in LTCF, in general, do not provide the appropriate intensity to improve the adaptative responses in the elderly ${ }^{5}$. Sedentary behaviour is associated with a decline in executive functions, a cognitive domain that is related to spatial navigation ${ }^{8,9}$.

Spatial navigation ability is one of several interrelated cognitive domains that require contributions from cognitive processes such as visual perception, learning, memory, and executive functions ${ }^{10,11}$. Spatial navigation can be subdivided into egocentric and allocentric domains. Egocentric navigation is related to the construction of a static mental map, in which each object has a place in the environment, and the spatial navigation of the beginning to the final is planned. On the other hand, allocentric navigation presents a fluid environment that is susceptible to the variations required for cognitive skills associated with mental flexibility and processing speed ${ }^{12}$.

Recent studies have shown that spatial navigation is a complex skill and an important marker of the progression of dementia. The allocentric frame is particularly related to the location of place cells, hippocampus, entorhinal, prefrontal and parietal cortexes, areas that commonly undergo degeneration in dementia ${ }^{13}$. The Floor Maze Test (FMT) is a new tool used to measures the capacity for path integration, planning and execution of tasks ${ }^{14}$. Better performance in the FMT has been associated with lower risk of cognitive decline and may be useful for assessing cognitive abilities, considering the low cost, ease of application and ecological characteristics ${ }^{10-12}$. Recently, Verghese et al. verified, that every 10 seconds in the FMT score is related to $25 \%$ increase in the risk of dementia ${ }^{15}$.

Notwithstanding the impairment of cognition promoted by the institutionalization of the older people, studies have demonstrated changes in the ability of these elderly individuals to deal with spatial information ${ }^{16}$. Thus, social isolation decreases responses to motor stimuli and cognitive health, indicating a possible influence on executive function, and the risk of dementia. Furthermore, many studies have revealed that dementia and cognitive disorders are underdiagnosed in the elderly in $\mathrm{LTCF}^{5}$. In the present study, we compared spatial navigation in three groups of elderly individuals: healthy, institutionalized, and patients with Alzheimer's disease (AD). We hypothesize that older people with dementia would present more significant impairment, followed by institutionalized, and then healthy older people.

\section{METHODS}

\section{Study design and participants}

In this cross-sectional study, 78 older subjects ( $>60$ years) were recruited from the community (healthy control group $=37$ ), long-term care facilities (LTCF) (institutionalized group = 19) and in the Center for Alzheimer's Disease and other Mental Disorders in Older Persons at the Institute of Psychiatry of the Federal University of Rio de Janeiro(AD group $=22$ ). AD was diagnosed by the medical staff composed by psychiatrists, trained to perform screening according to the Diagnostic and Statistical Manual of Mental Disorders Fourth Edition $(D S M-I V)^{17}$ and the National Institute of Neurological and Communicative Diseases and Stroke/Alzheimer's Disease and Related Disorders Association (NINCDS-ADRDA) ${ }^{18}$. Patients were classified as mild, moderate, or severe stage according to the Clinical Dementia Rating (CDR) ${ }^{19}$.

The control group was recruited from the community and they included individuals without neurological or psychiatric diseases, who were cognitively healthy by clinical evaluation and Mini-Mental State Examination (MMSE) ${ }^{20}$. The clinical assessment evaluated Neurological or psychiatric diseases. The institutionalized group was recruited from four (LTCF) in the city of Rio de Janeiro.

Participants with less than 4 years of schooling; severe dementia (for $\mathrm{AD}$ ) and diagnosis of any psychiatric or neurological disease (in the institutionalized group) were excluded from the study. This study was approved by the Ethics Committee of the Institute of Psychiatry of the Federal University of Rio de Janeiro (CAAE 42349815.0.00005263), and all participants provided written informed consent before participating in any procedure.

\section{Procedure and tests}

The global cognition was evaluated using Mini-Mental Statement Exam (MMSE) ${ }^{21}$, Clinical Dementia Rating (CDR) scale, Floor Maze Test (FMT) ${ }^{12}$, and 8 feet up and go test ${ }^{22}$.

The FMT measures skills of orientation, as it entails walking through a two-dimensional maze. Participants were positioned at the entry to the maze and then given instructions to find the only correct route to the exit. Two stages were evaluated: IMT, which is the time spent walking between the entry to the maze and the successful exit, and DMT, which is the time spent in repeating the second period, 
performed after 10 minutes, without planning. During this interval, the participants were not able to maintain visual contact with the maze. In this test, the time spent during each stage was measured and the wrong route was counted as an error.

8 foot-up-and-go test (8UG) assesses agility and dynamic balance and was validated ${ }^{22}$ as a tool to evaluate motor decline, balance reduction and premature risk of mobility loss and falls. The participant started from the sitting position in a chair, walked in a straight line for 8 feet, proceeded around a cone, and returned to the initial position, as quickly as possible. Three trials were performed, and the best performance was used in the analysis.

\section{Statistical analysis}

To verify normality and homoscedasticity, the KolmogorovSmirnov and Levene Test were applied, respectively. Demographic characteristics, MMSE, 8UG, and FMT (IMT and DMT) results were compared among groups using ANOVA or Kruskal-Wallis tests, with Bonferroni and Tamhane's T2 post hoc analyses. The chi-square test was used to identify gender distribution for each group. All statistical analyses were performed using SPSS version 19.0 and $p \leq 0.05$ was considered to indicate statistical significance.

\section{RESULTS}

We recruited a total of 117 and included 78 subjects. Among institutionalized, eight older people were excluded (dementia) and 31were not able to perform FMT (Figure 1).

There were no significant differences among the groups in terms of body mass index (BMI) and medication. The healthy group was younger than the institutionalized group $(p=0.01)$. However, there was no significant difference in age between the institutionalized and AD groups ( $p=0.56)$, as well as between healthy and AD groups $(p=0.015)$. We found a higher prevalence of women in the healthy group ( $p<$ 0.05). We also found significant difference in gender between

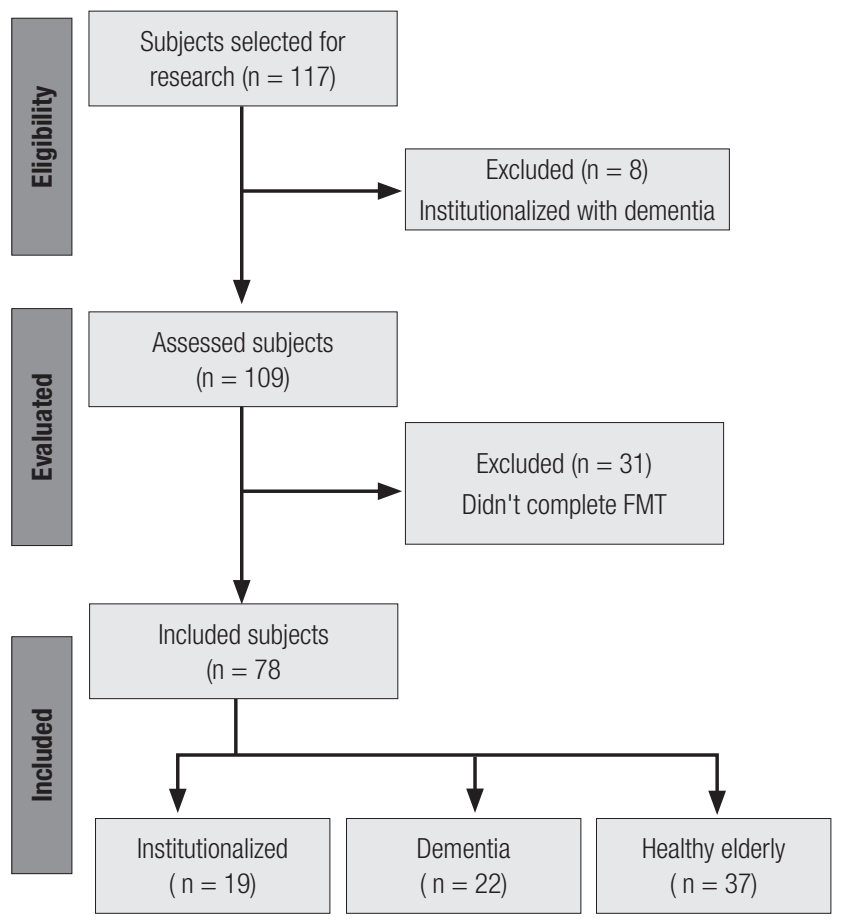

Figure 1. Flowchart of the study selection protocol.

healthy group and both $A D(p=0.001)$ and institutionalized $(p=0.002)$. As expected, the healthy group showed better cognitive performance than the institutionalized $(p<0.01)$ and $A D(p<0.01)$ groups, while there was no significant difference between the institutionalized and AD groups $(p=0.14)$. Moreover, the institutionalized group showed a poorer performance in the $8 \mathrm{UG}$ than the dementia $(p<0.01)$ and healthy $(p<0.01)$ groups (Table 1).

There was no significant difference between the AD and institutionalized groups in terms of the DMT results of the FMT $(p>0.13)$. However, the IMT results were better in the AD group than those in the institutionalized group $(p<0.01)$. As expected, the IMT and DMT were faster in the healthy group than those in the institutionalized and $A D$ groups $\left(X^{2}=31.23 ; p<0.01\right)$ and $\left(X^{2}=41.21 ; p<0.01\right)$ (Table 2).

Table 1. Demographic characteristics groups

\begin{tabular}{lcccc}
\hline & $\begin{array}{c}\text { Institutionalized } \\
(\mathbf{n}=\mathbf{2 3}) \\
\text { Mean } \pm \text { SD }\end{array}$ & $\begin{array}{c}\text { Dementia } \\
(\mathbf{n}=\mathbf{2 2}) \\
\text { Mean } \pm \text { SD }\end{array}$ & $\begin{array}{c}\text { Healthy } \\
(\mathbf{n}=\mathbf{3 7}) \\
\text { Mean } \pm \text { SD }\end{array}$ & $\mathbf{X}^{\mathbf{2}(\mathbf{p})}$ \\
\hline Age, $\mathrm{Y}$ & $84.3 \pm 6.77$ & $81.0 \pm 8.08$ & $75.2 \pm 8.43^{\mathrm{a}}$ & $12.10(\mathrm{p}=0.002)$ \\
Gender, N (Female \%) & $17(65.4 \%)$ & $11(50 \%)$ & $33(89.2 \%)^{\mathrm{a}, \mathrm{b}}$ & $13.02(\mathrm{p}=0.001)$ \\
$\mathrm{BM}^{+}, \mathrm{kg} / \mathrm{m}^{2}$ & $26.3 \pm 4.51$ & $25.9 \pm 4.28$ & $25,8 \pm 2,81^{\#}$ & $0.10(\mathrm{p}=0.901)$ \\
Medication, N & $8.2 \pm 4.40$ & $4.8 \pm 2.50$ & $2,4 \pm 2,04$ & $1.59(\mathrm{p}=0.451)$ \\
MMSE, score & $22.7 \pm 5.90$ & $21.6 \pm 3.91$ & $28.3 \pm 1.89^{\mathrm{a}, \mathrm{b}}$ & $36.72(\mathrm{p}<0.001)$ \\
8UG, sec & $16.0 \pm 6.02$ & $8.2 \pm 2.50^{\mathrm{a}}$ & $7.1 \pm 2.87^{\mathrm{a}}$ & $31.74(\mathrm{p}<0.001)$ \\
\hline
\end{tabular}

+ 6 participants are excluded to missed odds by medical records; BMI: body mass index; MMSE: Mini Mental State Exam. \# F value (ANOVA); 8UG: 8-foot up and go test.

${ }^{\mathrm{a}} \mathrm{p}<0.05$ compared to institutionalized group; ${ }^{\mathrm{b}} \mathrm{p}<0.05$ compared to dementia group. 
Table 2. Group comparisons of the Floor Maze Test immediate and delay times

\begin{tabular}{lcccc}
\hline & $\begin{array}{c}\text { Institutionalized group } \\
\text { Median (min-max) }\end{array}$ & $\begin{array}{c}\text { Dementia group } \\
\text { Median (min-max) }\end{array}$ & $\begin{array}{c}\text { Healthy group } \\
\text { Median (min-max) }\end{array}$ & \multicolumn{1}{c}{$\mathbf{X}^{\mathbf{2}}(\mathbf{p})$} \\
\hline FMT Immediate $(\mathrm{s})$ & $114(17-274)$ & $59,(20-188)^{\mathrm{a}}$ & $21.06(9.65-196)^{\mathrm{a}, \mathrm{b}}$ & $31.22(\mathrm{p}<0.001)$ \\
FMT Delay $(\mathrm{s})$ & $88(17-255)$ & $86.51(16-281)$ & $16.34(9.46-169)^{\mathrm{a}, \mathrm{b}}$ & $41.20(\mathrm{p}<0.001)$ \\
\hline
\end{tabular}

${ }^{\mathrm{a}} \mathrm{p}<0.05$ compared to institutionalized group; ${ }^{\mathrm{b}} \mathrm{p}<0.05$ compared to dementia group.

\section{DISCUSSION}

In the present study we compared spatial navigation ability in elderly healthy controls, institutionalized individuals and patients with AD. Our results showed similar cognitive impairment in older adults living in LTCFs and patients with $A D$, suggesting that elderly individuals in LTCF have a high risk of dementia, although few screening psychiatric evaluations are implemented, leading to underdiagnosis in this population. Several studies have shown a cognitive decline in institutionalized elderly individuals ${ }^{3-7}$, and the hospitalization and social isolation have also been shown to have significant impacts ${ }^{23}$. Among other factors, the increased sedentary behaviour correlates with motor and cognitive decline in this population ${ }^{24,25}$. Institutionalization appears to contribute to the decline in executive function and motor skills associated with the reduction in mobility and social interaction of the elderly, which does not necessarily occur in the dementia group. The older people living in LTCF seem to experience more impairment of executive function than older adults living at community, while there is no difference in the decrease in memory ability between the groups.

Our results corroborate previous studies, showing that impairment in IMT and DMT FMT performance is associated with $A D^{11}$ and risk of dementia ${ }^{15}$. Moreover, longer times in FMT have been associated with cognitive impairment, with particular effects on executive functions, attention, learning and memory ${ }^{10}$. Verghese et al. showed that IMT in FMT was a stronger predictor of dementia than $\mathrm{DMT}^{15}$. One possible explanation is the complexity of integration of the executive functions and dynamic balance in the IMT. Indeed, the DMT seems to be more related to hippocampus activation and memory than the IMT.

In this study, the institutionalized elderly group showed worse results in $8 \mathrm{UG}$ compared to that of the communitydwelling older individuals with dementia. Indeed, Maseda et al. ${ }^{26}$ suggest that the institutionalization process could provide to the impairment of physical capacities. A decline in motor function among elderly people with dementia was also identified by Plácido et al. ${ }^{27}$ and de Oliveira Silva et al. ${ }^{28}$.

The relationship of the MMSE and the $8 \mathrm{UG}$ with the IMT and DMT suggests a relevant influence of motor and cognitive skills in the FMT, reinforcing the ability of this test to predict physical and cognitive decline. Particularly, in low- and middle-income countries, where dementia is widely underdiagnosed, simple strategies to screen the cognitive decline are urgently required. Estimated that $77 \%$ of people with dementia in Latin America countries have not been diagnosed ${ }^{29}$. The absence of diagnosis can be even worse in LTCF, considering the cognitive impairment observed after institutionalization ${ }^{5}$.

The implementation of strategies that encourage cognitive and motor engagement of the older people in LTCF may protect their physical and mental health, contributing to improved functionality and independence. It should be noted that this study was limited by the small sample size and the cross-sectional design. The study lacks some information in the medical records, as well as the duration of disease and institutionalization. The recruitment of the control group can present a possible bias, given the lack of control by sex and age. Finally, it is not possible to guarantee that the institutionalized group was not dementia, considering the underdiagnosis observed in Brazil.

\section{CONCLUSION}

Our results suggest that the institutionalized older people have a deficit in the spatial navigation ability, cognitive functions and motor skills, similar to that observed in $A D$ patients. Possible underdiagnosis should be considered in institutionalized older people. Studies investigating the cognitive function before and after institutionalization are needed to better understand a possible relationship between cognitive decline and long-term social and nursing care facilities, especially in low-to-middle income countries.

\section{CONFLICT OF INTERESTS}

The authors declare that they have no conflict of interests.

\section{ACKNOWLEDGMENT}

This work was supported by the Conselho Nacional de Desenvolvimento Científico e Tecnológico under Grant (CNPq-301483/2016-7) and Fundação Carlos Chagas Filho de 
Amparo à Pesquisa do Estado do Rio de Janeiro under Grant (Faperj-E26/202.523/2019).

The study was conducted at the Institute of Psychiatry, Federal University of Rio de Janeiro, Rio de Janeiro, Brazil.

\section{REFERENCES}

1. Barnes DE, Yaffe $K$. The projected effect of risk factor reduction on Alzheimer's disease prevalence. Lancet Neurol. 2011;10(9):819-28.

2. Wimo A, Winblad B, Jönsson L. The worldwide societal costs of dementia: Estimates for 2009. Alzheimers Dement. 2010;6(2):98-103.

3. Burdick KE, Endick CJ, Goldberg JF. Assessing cognitive deficits in bipolar disorder: are selfreports valid? Psychiatry Res. 2005;136(1):43-50.

4. Wilson R, Scherr P, Schneider J, Tang Y, Bennett D. Relation of cognitive activity to risk of developing Alzheimer disease. Neurology. 2007;69(20):1911-20.

5. González-Colaço Harmand M, Meillon C, Rullier L, Avila-Funes JA, Bergua V, Dartigues JF, et al. Cognitive decline after entering a nursing home: a 22-year follow-up study of institutionalized and noninstitutionalized elderly people. J Am Med Dir Assoc. 2014;15(7):504-8.

6. Harsányiová M, Prokop P. Living condition, weight loss and cognitive decline among people with dementia. Nurs Open. 2018;5(3):275-84.

7. Schultz SK, Ellingrod VL, Turvey C, Moser DJ, Arndt S. The influence of cognitive impairment and behavioral dysregulation on daily functioning in the nursing home setting. Am J Psychiatry. 2003;160(3):582-4.

8. Lipardo DS, Aseron AMC, Kwan MM, Tsang WW. Effect of exercise and cognitive training on falls and fall-related factors in older adults with mild cognitive impairment: a systematic review. Arch Phys Med Rehabil. 2017;98(10):2079-96.

9. Ble A, Volpato S, Zuliani G, Guralnik JM, Bandinelli S, Lauretani F, et al. Executive function correlates with walking speed in older persons: the InCHIANTI study. J Am Geriatr Soc. 2005;53(3):410-5.

10. Tangen GG, Engedal K, Bergland A, Moger TA, Mengshoel AM. Relationships between balance and cognition in patients with subjective cognitive impairment, mild cognitive impairment, and Alzheimer disease. Phys Ther. 2014;94(8):1123-34.

11. Zanco M, Placido J, Marinho V, Ferreira JV, Oliveira F, Monteiro-Junior RS, et al. Spatial Navigation in the Elderly with Alzheimer's Disease: A Cross-Sectional Study. J Alzheimers Dis. 2018;66(4):1683-94.

12. Sanders AE, Holtzer R, Lipton RB, Hall C, Verghese J. Egocentric and exocentric navigation skills in older adults. J Gerontol A Biol Sci Med Sci. 2008;63(12):1356-63.

13. Martelli D, Prado A, Xia B, Verghese J, Agrawal SK. Development of a Virtual Floor Maze Test - Effects of Distal Visual Cues and Correlations With Executive Function in Healthy Adults. IEEE Trans Neural Syst Rehabil Eng. 2019;27(10):2229-36.
14. Lithfous $\mathrm{S}$, Dufour $\mathrm{A}$, Després 0 . Spatial navigation in normal aging and the prodromal stage of Alzheimer's disease: insights from imaging and behavioral studies. Ageing Res Reiews. 2013;12(1):201-13.

15. Verghese J, Lipton R, Ayers E. Spatial navigation and risk of cognitive impairment: A prospective cohort study. Alzheimers Dement. 2017;13(9):985-92.

16. van der Voordt D. Losing your way in the nursing home: spatial orientation from an architectural viewpoint. A review. Tijdschr Gerontol Geriatr. 1993;24(6):220.

17. American Psychiatric Association. DSM-5: Manual Diagnóstico e Estatístico de Transtornos Mentais: Porto Alegre: Artmed; 2014.

18. McKhann GM, Knopman DS, Chertkow H, Hyman BT, Jack Jr CR, Kawas CH, et al. The diagnosis of dementia due to Alzheimer's disease: Recommendations from the National Institute on Aging-Alzheimer's Association workgroups on diagnostic guidelines for Alzheimer's disease. Alzheimers Dement. 2011;7(3):263-9.

19. Chaves MLF, Camozzato AL, Godinho C, Kochhann R, Schuh A, de Almeida VL, et al. Validity of the clinical dementia rating scale for the detection and staging of dementia in Brazilian patients. Alzheimer Dis Assoc Disord. 2007;21(3):210-7.

20. Bertolucci PH, Brucki SM, Campacci SR, Juliano Y. 0 mini-exame do estado mental em uma população geral: impacto da escolaridade. Arq Neuro-psiquiatr. 1994;52(1):1-7.

21. Folstein MF FS, Mchugh PR. "Mini-mental state": A practical method for grading the cognitive state of patients for the clinician. Psychiatry Res. 1975;12(189-98).

22. Rikli RE, Jones CJ. Development and validation of a functional fitness test for communityresiding older adults. J Aging Phys Act. 1999;7(2):129-61.

23. Béland F, Zunzunegui MV, Alvarado B, Otero A, del Ser T. Trajectories of cognitive decline and social relations. J Gerontol B Psychol Sci Soc Sci. 2005;60(6):P320-30.

24. Volkers KM, Scherder EJ. Impoverished environment, cognition, aging and dementia. Rev Neurosci. 2011;22(3):259-66.

25. de Macedo LDED, De Oliveira TCG, Soares FC, Bento-Torres J, Bento-Torres NV0, Anthony $D C$, et al. Beneficial effects of multisensory and cognitive stimulation in institutionalized elderly: 12-months follow-up. Clin Interv Aging. 2015;10:1351-9.

26. Maseda A, Balo A, Lorenzo-López L, Lodeiro-Fernández L, Rodríguez-Villamil JL, MillánCalenti JC. Cognitive and affective assessment in day care versus institutionalized elderly patients: a 1-year longitudinal study. Clin Interv Aging. 2014;9:887-94.

27. Plácido J, Ferreira JV, Oliveira F, Sant'Anna P, Monteiro-Junior RS, Laks J, et al. Association among 2-min step test, functional level and diagnosis of dementia. Dement Neuropsychol. 2019;13(1):97-103.

28. de Oliveira Silva F, Ferreira JV, Plácido J, Chagas D, Praxedes J, Guimarães C, et al. Stages of mild cognitive impairment and Alzheimer's disease can be differentiated by declines in timed up and go test: A systematic review and meta-analysis. Arch Gerontol Geriatr. 2019;85:103941.

29. Nakamura AE, Opaleye D, Tani G, Ferri (P. Dementia underdiagnosis in Brazil. Lancet. 2015;385(9966):418-9. 